\title{
HOT TOPICS
}

\section{Intra-individual changes in methylome profiles: an epigenetic 'scar' of early-life adversity?}

\author{
Ali Mortazavi ${ }^{1}$ and Tallie Z. Baram (iD ${ }^{2}$ \\ Neuropsychopharmacology (2019) 45:1; https://doi.org/10.1038/s41386-019-0496-3
}

Whereas genetics plays a critical role in vulnerability and resilience to mental illness, the contribution of early-life experiences to these outcomes has been strongly suggested in humans and supported by studies in animal models [1]. Early-life adversity (ELA), including poverty, chaotic environment, and abuse, predicts vulnerability to depression as well as lower cognitive function [1, 2]. Yet, at the individual level it is not possible to predict which child exposed to ELA will be vulnerable later in life. Lacking are predictive biomarkers that enable early diagnosis, prevention, and intervention [1-3].

There is evidence that the mechanisms by which early-life experiences influence the function of neurons (and neuronal networks) underlying vulnerability or resilience involve alterations of the repertoire and levels of gene expression via epigenetic processes. Among those, changes in DNA methylation at the individual gene and genomic scale may partially govern gene expression. It is not possible to examine DNA from brain samples in children, so that current approaches have largely employed peripheral cells including white blood cells or buccal swabs (mixed epithelial/white blood cells). Numerous studies have compared DNA methylation profiles from individuals experiencing adversity to those raised in 'typical' environments; yet cross-sectional studies are challenged by the large inter-individual variance of DNA methylation profiles.

We employed a novel intra-individual approach by testing buccal cell DNA methylation profiles of the same individual sampled twice: immediately before and after a defined period of ELA [3]. We imposed ELA of defined onset and termination during established sensitive developmental periods by raising rat pups for a week (postnatal days 2-10) in cages with limited bedding and nesting materials (simulated poverty). Prior work established that this experience provokes enduring anhedonia-like behaviors and significant deficits in hippocampus-dependent memory $[4,5]$. Controls were sampled in parallel.

Traditional analyses of DNA methylation profiles across samples detected the effects of age, but did not distinguish pups exposed to ELA from controls. In contrast, DNA methylation changes between paired DNA samples from the same individual rat illustrated the impact of ELA. In ELA animals, methylation increased (predicting reduced expression) in genes coding for critical cellular/metabolic enzymes, ion channels, and receptors, whereas genes involved in pathways of death, inflammation, and cell-fate were less methylated, indicating their potential upregulation [3]. Thus ELA left an epigenetic 'signature': large-scale transcription-driven alterations of cellular fate, growth and function, consistent with -and potentially predicting-pathology.
This work, employing rodents, provides proof of principle for the potential power of intra-individual methylomics to identify epigenetic signatures of ELA which predict subsequent emotional and memory problems. The approach is translatable to the clinic $[5,6]$, as methylomic signatures in individual children might predict vulnerability or resilience to stress and/or mental illness. Current studies in infants are obtaining buccal-swab DNA twice, during the second week of life and at 1 year. ELA, derived from unpredictable environmental and maternal signals $[5,6]$ is assessed, and cognitive and emotional outcomes of individual infants are examined longitudinally.

In summary, intra-individual methylomics identifies epigenetic 'scars' and 'kisses' of early adversity, which may provide a predictive marker for vulnerability and resilience to certain mental illnesses.

\section{FUNDING AND DISCLOSURE}

The authors' research is supported in part by $\mathrm{NIH}$ grants $\mathrm{RO} 1$ MH73136, NS28912 and P50 MH096889. The authors declare no competing interests.

\section{ADDITIONAL INFORMATION}

Publisher's note: Springer Nature remains neutral with regard to jurisdictional claims in published maps and institutional affiliations.

\section{REFERENCES}

1. Transformative Neurodevelopmental Research in Mental Illness: Report of the NAHMC. Accessed 6 July 2019.

2. Short AK, Baram TZ. Early-life adversity and neurological disease: age-old questions and novel answers. Nature Rev Neuro, 2019 (in press). https://doi.org/ 10.1038/s41582-019-0246-5.

3. Jiang S, Kamei N, Bolton JL, Ma X, Stern HS, Baram TZ, Mortazavi A. Intra-individual methylomics detects the impact of early-life adversity. Life Sci Alliance. 2019 https://doi.org/10.26508/lsa.201800204.

4. Bolton JL, Molet J, Regev L, Chen Y, Rismanchi N, Haddad E, et al. Anhedonia following early-life adversity involves aberrant interaction of reward and anxiety circuits and is reversed by partial silencing of amygdala corticotropin-releasing hormone gene. Biol Psychiatry 2018;83:137-147.

5. Davis EP, Stout SA, Molet J, Vegetabile B, Glynn LM, Sandman CA, et al. Exposure to unpredictable maternal sensory signals influences cognitive development across species. Proc. Natl Acad. Sci. USA. 2017;114:10390-10395.

6. Glynn LM, Stern HS, Howland MA, Risbrough VB, Baker DG, Nievergelt CM, et al. Measuring novel antecedents of mental illness: the questionnaire of unpredictability in childhood. Neuropsychopharmacology 2019;44:876-882.

\footnotetext{
${ }^{1}$ Departments of Developmental and Cell Biology, University of California-Irvine, Irvine, CA 92697-4475, USA and ${ }^{2}$ Departments of Pediatrics, Anatomy/Neurobiology, Neurology, University of California-Irvine, Irvine, CA 92697-4475, USA

Correspondence: Ali Mortazavi (ali.mortazavi@uci.edu) or Tallie Z. Baram (tallie@uci.edu)
}

Published online: 30 August 2019 